\title{
Evaluation of the Frequency of Obesity and Associated Factors in Children of Obese and Overweight Mothers
}

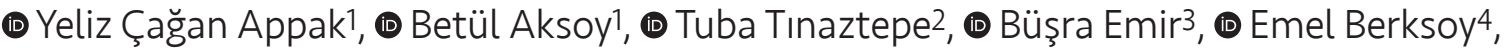 \\ (1) Oya Baltalı2, (1) Maşallah Baran1,5 \\ 1'zzmir University of Health Sciences, Tepecik Training and Research Hospital, Clinic of Pediatric Gastroenterology, İzmir, Turkey \\ 2ìzmir University of Health Sciences, Tepecik Training and Research Hospital, Clinic of Pediatric, İzmir, Turkey \\ 3izmir Katip Çelebi University Faculty of Medicine, Department of Biostatistics, İzmir, Turkey \\ 4 izmir University of Health Sciences, Tepecik Training and Research Hospital, Clinic of Pediatric Emergency, İzmir, Turkey \\ 5izmir Katip Çelebi University Faculty of Medicine, Department of Pediatric Gastroenterology, İzmir, Turkey
}

\begin{abstract}
Aim: The mother is an important determinant of the nutrition of her children. The aim of this study is to evaluate the relationship between obese or overweight mothers, their socio-demographic status and appetite on the anthropometric measurements of their children, and to evaluate the relationship between breastfeeding duration, initiation time of a complementary diet and children's body mass index (BMI) classification.

Materials and Methods: Children whose ages were between 2 and 5 years old, with no additional chronic disease, were included. The sociodemographic data, anthropometric measurements and appetites of the children and their mothers were determined. Obese or overweight mothers and mothers with normal BMI were studied as two separate groups. The duration of breastfeeding and initiation time of a complementary diet for the children was classified as $<4$ months, 4-6 months and $>6$ months.

Results: A total of 182 children (109 with obese and overweight mothers and 73 with mothers with normal BMI) were included. The ratio of overweight and obese children among the group of obese and overweight mothers was higher. When the weight, weight percentile and weight standard deviation score values of the obese or overweight mothers were compared with their children, a moderately statistically significant positive correlation was found. The ratio of overweight and obese children among the group of employed mothers, and the ratio of underweight children among the group of unemployed mothers, was high. A significant relationship was found between maternal appetite and the BMI classification of their children. No statistically significant difference was found between breastfeeding duration, initiation time of a complementary diet and children's BMI classification.

Conclusion: It was determined that the mother's characteristics of having a BMI classification of overweight or obese, excessive appetite and being employed may be risk factors in the development of overweight and obese children.
\end{abstract}

Keywords: Obesity, mother, child, overweight 


\section{Introduction}

The increase in obese and overweight children is an important health problem all over the world. In Turkey, especially in recent years, the prevalence of obesity has increased in children and adolescents. It is reported that 14.2-16.1\% of children are overweight, and $8.3-10 \%$ are obese in Turkey $(1,2)$. Parental obesity is thought to be a risk factor for childhood obesity (3). Sharing the same genetic burden and environmental conditions are influencing factors for parents and children (4).

Parental weight change is an independent predictor of child weight change (5). However, positive weight change in the mother had a more dominant influence than did a father's positive weight change (5). The mother is generally the principle responsible parent for the care of the child, and her knowledge and practices surrounding nutrition can be an influential factor in her child's development, as well as her own body composition $(5,6)$. The sociocultural status of the mother, her level of knowledge and practices around nutrition, her employment status and how she acts as a role-model for her child regarding nutrition can shape the nutritional characteristics of the child and, ultimately, the child's body composition (7). In a systematic review, it is reported that breastfeeding has a small but consistent protective effect against obesity in children (8). However, some studies have reported an inverse relationship between breastfeeding and obesity (8). Additionally, it has been reported that complementary feeding, when initiated earlier than 4 months, increased the risk of being overweight and obese during childhood (9). For these reasons, the aim of this study is to evaluate the effect of having an obese or overweight mother, sociodemographic status and the appetite of the mother, on the anthropometric measurements of the child. The second aim is to evaluate the relationship between breastfeeding duration, initiation time of a complementary diet and children's BMI classification.

\section{Materials and Methods}

Children who were admitted to the pediatric gastroenterology and general pediatric outpatient clinic between August and November 2018 who were between the ages of 2 and 5 years and had no additional chronic disease were included in the study. The socio-demographic data of the children and their mothers were determined. The mothers' education level, employment status, appetite, level of knowledge about child nutrition, breastfeeding duration, initiation time of complementary feeding and family income were evaluated. The monthly income levels were grouped as $\leq 1600$ Turkish Lira (TL), 1600-2500 TL, 2500-5000 TL and >5000 TL, based on the minimum wage. Appetite was classified and recorded as: very low (0 points), low (1 point), normal ( 3 points), strong (4 points), very strong ( 5 points). The appetite of the mother and the child were determined according to the score given by the mother.

The height and weight of the children and their mothers were measured by the same team using the same equipment. The weight, weight percentile, weight standard deviation score (SDS) and body mass index (BMI) of the children and their mothers were determined. The BMI of mothers and children were calculated by weight $(\mathrm{kg}) / \mathrm{height}$ squared $\left(\mathrm{m}^{2}\right)$. The BMI of the children was rated as follows; $>95$ percentile=obese, $85-95$ percentile $=$ overweight, 5-85 percentile $=$ normal, $<5$ percentile=underweight $(10,11)$. The $\mathrm{BMI}$ of the mothers was classified as follows: $>30=$ obese, $25-29.99=$ overweight, $18.5-24.99=$ normal and $<18.5=$ =underweight (http://www.who.int/mediacentre/ factsheets/fs311/en). Children whose mothers were underweight were not included in the study. Children whose mothers were considered obese or overweight and children whose mothers' BMI was within the normal range were studied as two separate groups. The duration of breastfeeding and initiation time of a complementary diet for the children was classified as $<4$ months, $4-6$ months and $>6$ months. The anthropometric measurements, parents' socio-demographic data, duration of breastfeeding and initiation time of a complementary diet and appetite were compared between the two groups. The relationship between the anthropometric measurements of the mothers and their children was also evaluated. Informed consent was obtained from all mothers participating in the study. Ethics committee approval was obtained from the Ethics Committee of Izmir University of Health Sciences, Tepecik Training and Research Hospital (approval number: 2019/725).

\section{Statistical Analysis}

All statistical analyses were performed using the IBM SPSS Statistics 25 package program (IBM Corp., Armonk, New York, USA). Data are presented as count (n), percent (\%), mean, SD ( $\bar{X} \pm$ SD) and median $25 \%-75 \%$ quartiles $[M$ $\left.\left(Q_{1}-Q_{3}\right)\right]$. Shapiro-Wilk's test was used and a histogram and $Q-Q$ plot were examined to assess the data normality. Mann-Whitney $U$ test was used to compare the differences between the two groups for the children's age and BMI (percentile). The relationship between variables was 
evaluated by Spearman correlation analysis. The relationship between categorical variables that have two categories or more than two categories were analysed using Pearson chisquare test and Continuity Correction test. A boxplot graph was used to show the shape of the distribution of breastfeeding duration (months) according to groups based on the children's BMI classification. A bar graph was used to visually compare data among categories concerning breastfeeding duration ( 3 categories), mother's appetite ( 5 categories) and initiation time of a complementary diet (3 categories).

\section{Results}

A total of 182 children with 109 obese or overweight mothers and 73 mothers who had normal BMI were included in the study. The socio-demographic and anthropometric findings of the children and mothers are shown in Table I. There were statistically significant differences, in terms of the BMI percentiles of the children, between the group of children with obese or overweight mothers and the group with mothers with normal BMI $(p=0.011)$ (Table I). According to the children's BMI classifications, there is no significant relationship between the children of obese or overweight mothers and the children of mothers with normal BMI $(p=0.170)$. However, the ratio of overweight and obese children among the group of obese and overweight mothers was higher than among the group with normal BMI mothers (Table II). A statistically significant difference was found between the BMI classification of the children with employed versus unemployed mothers $(p=0.015)$. The distribution of overweight and obese children among the group of employed mothers and the distribution of underweight children among the group of unemployed mothers was high (Table II). When the weight, weight percentile and weight SDS values of the obese or overweight mothers were compared with their children, a moderately statistically significant positive correlation was found $\left(r_{s}=0.215, p=0.025 ; r_{s}=0.319, p=0.001 ; r_{s}=0.319\right.$, $p=0.001)$. A significant relationship was found between maternal appetite and the BMI classification of the child $(p=0.005)$. Among the children of mothers with very good appetites, $18.5 \%$ were overweight and $20.4 \%$ were obese (Table II).

No statistically significant difference was found between the breastfeeding duration and the children's BMI classification $(p=0.687)$ (Figure 1, Table II). However, the ratio of overweight and obese children among the group of children breastfed for less than 4 months was higher than the group of children breastfed for more than 6 months
(Table II). When the children were evaluated according to the initiation time of a complementary diet, no significant difference was found $(p=0.375)$ (Table II).

Table I. Socio-demographic and anthropometric findings of the children in the groups

\begin{tabular}{|c|c|c|c|}
\hline & \multicolumn{2}{|l|}{ Groups } & \\
\hline & $\begin{array}{l}\text { Obese or } \\
\text { overweight } \\
\text { mother }(n=109)\end{array}$ & $\begin{array}{l}\text { Mother with } \\
\text { normal BMI } \\
(n=73)\end{array}$ & \\
\hline \multicolumn{4}{|l|}{ Children } \\
\hline & $\bar{X} \pm S D$ & $\bar{X} \pm S D$ & \\
\hline & $M\left(Q_{1}-Q_{3}\right)$ & $M\left(Q_{1}-Q_{3}\right)$ & $\mathrm{p}$ value \\
\hline \multirow[t]{2}{*}{ Age } & $3.53 \pm 1.02$ & $3.59 \pm 1.05$ & \multirow[b]{2}{*}{$0.679^{+}$} \\
\hline & $\begin{array}{l}3.50 \\
(2.83-4.50)\end{array}$ & $\begin{array}{l}3.50 \\
(2.75-4.50)\end{array}$ & \\
\hline \multirow{3}{*}{ BMI percentile } & $50.63 \pm 36.63$ & $37.25 \pm 33.90$ & \multirow[b]{2}{*}{$0.011^{+}$} \\
\hline & $\begin{array}{l}56.36 \\
(13.00-89.03)\end{array}$ & $\begin{array}{l}28.10 \\
(4.36-69.89)\end{array}$ & \\
\hline & $(n, \%)$ & $(n, \%)$ & \\
\hline \multicolumn{4}{|l|}{ Gender } \\
\hline Girls & $60(55.0)$ & $34(46.6)$ & \multirow{2}{*}{$0.262^{\dagger}$} \\
\hline Boys & $49(45.0)$ & $39(53.4)$ & \\
\hline \multicolumn{4}{|l|}{ Mother } \\
\hline & $\bar{X} \pm S D$ & $\bar{X} \pm S D$ & \\
\hline & $M\left(Q_{1}-Q_{3}\right)$ & $M\left(Q_{1}-Q_{3}\right)$ & \\
\hline \multirow{3}{*}{ Age } & $31.81 \pm 5.40$ & $31.53 \pm 5.54$ & \multirow[b]{2}{*}{$0.997^{+}$} \\
\hline & $\begin{array}{l}31.00 \\
(28.00-34.00)\end{array}$ & $\begin{array}{l}32.00 \\
(27.00-36.00)\end{array}$ & \\
\hline & $(n, \%)$ & $(n, \%)$ & \\
\hline \multicolumn{4}{|l|}{ Education level } \\
\hline Uneducated & $9(8.3)$ & $8(11.0)$ & \multirow{4}{*}{$0.436^{\dagger}$} \\
\hline Primary school & $64(58.7)$ & $37(50.7)$ & \\
\hline High school & $17(15.6)$ & $9(12.3)$ & \\
\hline University & $19(17.4)$ & $19(26.0)$ & \\
\hline \multicolumn{4}{|c|}{ Employment status } \\
\hline Employed & $29(26.6)$ & $20(27.4)$ & \multirow{2}{*}{$1.000^{*}$} \\
\hline Unemployed & $80(73.4)$ & $53(72.6)$ & \\
\hline \multicolumn{3}{|c|}{ Family income level } & \multirow{5}{*}{$0.993^{+}$} \\
\hline $1600 \mathrm{TL}$ & $37(33.9)$ & $25(34.2)$ & \\
\hline $1601-2500 \mathrm{TL}$ & 37 (33.9) & $25(34.2)$ & \\
\hline 2501-5000 TL & $15(13.8)$ & $9(12.3)$ & \\
\hline$>5000 \mathrm{TL}$ & $20(18.3)$ & $14(19.2)$ & \\
\hline
\end{tabular}

${ }^{+}$Mann-Whitney $\mathrm{U}$ test, ${ }^{\top}$ Pearson chi-square test, ${ }^{*}$ Continuity correction BMI: Body mass index 


\section{Discussion}

In this study, obese and overweight mothers who were employed and had a high appetite were found to have more obese and overweight children. Additionally, the children who were breastfed for less than 4 months were more

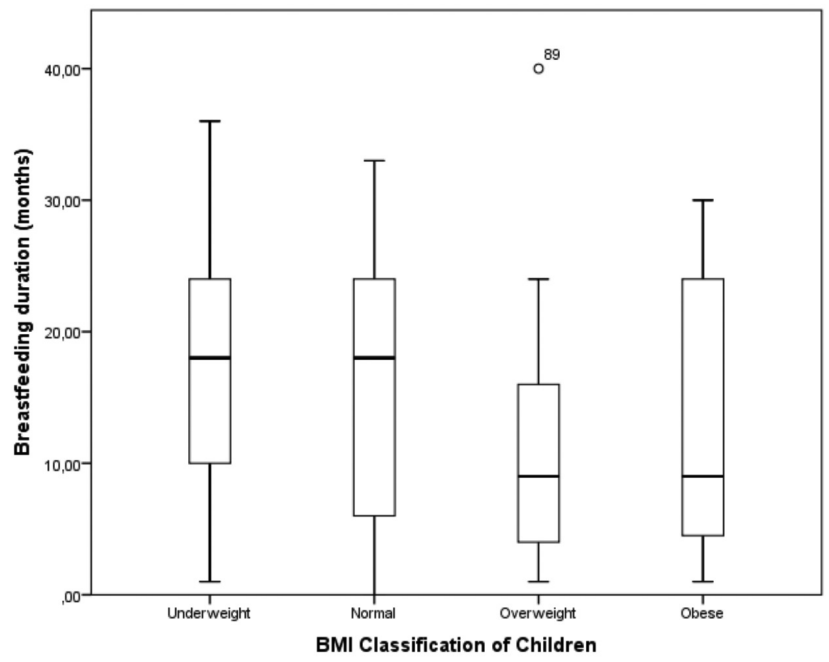

Figure 1. Boxplot of breastfeeding duration (months) and Children's body mass index classification

BMI: Body mass index likely to be obese and overweight than children who were breastfed for more than 6 months.

Parents are important as a role model in the physical appearance and health of their children (12). Parental obesity has been shown to increase the risk of the development of obesity in children $(13,14)$. The mother is especially the determinant of nutrition for her child, as she is the principal caregiver and the person shaping nutrition (6). Stunkard et al. (15) showed a weak relationship between the weight of mothers and the weight of their children in the first 2 years. The first years are a transitional period in which the prenatal environmental impact decreases and the genetic and shared common environment and parental characteristics become more pronounced (4). Therefore, this study did not include children less than 2 years of age.

In a study in which children under 5 years of age were followed for about 14 years, it was shown that mothers' positive weight gain increased the likelihood of positive weight gain in pre-school and school children. However, no similar relationship was found between fathers and their children (5). In our study, we found a positive correlation between the weight, weight percentile and weight SDS values of the obese or overweight mothers and their

Table II. The relationship between breastfeeding duration, initiation time of a complementary diet, maternal appetite, mother's body mass index classification, mother's working status and body mass index classification of children

\begin{tabular}{|c|c|c|c|c|c|c|c|c|c|c|}
\hline & & \multicolumn{8}{|c|}{ BMI classification of children } & \multirow{3}{*}{$\mathrm{p}$ value } \\
\hline & & \multicolumn{2}{|c|}{ Obese } & \multicolumn{2}{|c|}{ Overweight } & \multicolumn{2}{|c|}{ Normal } & \multicolumn{2}{|c|}{ Underweight } & \\
\hline & & $\mathbf{n}$ & $\%$ & $\mathbf{n}$ & $\%$ & $\mathbf{n}$ & $\%$ & $\mathbf{n}$ & $\%$ & \\
\hline \multirow{3}{*}{ Breastfeeding duration } & $<4$ months & 4 & 15.4 & 4 & 15.4 & 15 & 57.7 & 3 & 11.5 & \multirow{3}{*}{$0.687^{\dagger}$} \\
\hline & 4-6 months & 2 & 13.3 & 3 & 20 & 8 & 53.4 & 2 & 13.3 & \\
\hline & $>6$ months & 13 & 9.5 & 14 & 10.2 & 79 & 57.7 & 31 & 22.6 & \\
\hline \multirow{3}{*}{$\begin{array}{l}\text { Initiation time of complementary } \\
\text { diet }\end{array}$} & $<4$ months & 2 & 40 & 0 & 0.0 & 3 & 60 & 0 & 0.0 & \multirow{3}{*}{$0.375^{\dagger}$} \\
\hline & 4-6 months & 5 & 12.5 & 5 & 12.5 & 22 & 55 & 8 & 20 & \\
\hline & $>6$ months & 12 & 8.8 & 17 & 12.4 & 79 & 57.6 & 29 & 21.2 & \\
\hline \multirow{5}{*}{ Maternal appetite } & Very low & 0 & 0.0 & 0 & 0.0 & 0 & 0.0 & 1 & 100 & \multirow{5}{*}{$0.005^{\dagger}$} \\
\hline & Low & 2 & 20 & 0 & 0.0 & 3 & 30 & 5 & 50 & \\
\hline & Normal & 1 & 2.4 & 6 & 14.3 & 27 & 64.3 & 8 & 19 & \\
\hline & Strong & 5 & 6.6 & 6 & 8 & 46 & 61.4 & 18 & 24 & \\
\hline & Very strong & 11 & 20.4 & 10 & 18.5 & 28 & 51.9 & 5 & 9.2 & \\
\hline \multirow{2}{*}{$\begin{array}{l}\text { BMI classification } \\
\text { of mothers }\end{array}$} & Obese or overweight & 14 & 12.8 & 16 & 14.7 & 61 & 56.0 & 18 & 16.5 & \multirow{2}{*}{$0.170^{+}$} \\
\hline & Normal & 5 & 6.8 & 6 & 8.2 & 43 & 58.9 & 19 & 26.0 & \\
\hline \multirow{2}{*}{ Mother's working status } & Employed & 7 & 14.3 & 11 & 22.4 & 26 & 53.1 & 5 & 10.2 & \multirow{2}{*}{$0.015^{\dagger}$} \\
\hline & Unemployed & 12 & 9.0 & 11 & 8.3 & 78 & 58.6 & 32 & 24.1 & \\
\hline
\end{tabular}

${ }^{\dagger}$ Pearson chi-square test

BMI: Body mass index 
children. Also, BMI percentiles were higher in the children of obese or overweight mothers.

It has been shown that young mothers with low education levels are not aware of their weight status and do not worry that their children are overweight (16). In a study from Sweden, it was reported that the children of obese and low-educated parents were at risk of the development of obesity (17). In a study from the United States, the relationship between the number of a mother's working hours (for mothers with higher education levels) and child BMI was associated with the child's duration of television viewing (18). In this study, the number of obese and overweight children was higher for employed mothers, and the number of underweight children was higher for unemployed mothers. In children between 2 and 5 years of age, have been reported to be more important in the prevention of obesity, rather than longer working hours, more standard working hours for parents and reduced access of children to sugary drinks (19).

It has been reported that exclusive breastfeeding has a positive effect on the weight of children, as well as their weight in adolescence and adulthood (20). There is also a positive relationship between the mother's >30 BMI and a duration of less than 4 months breastfeeding (21). In a study that evaluated 5 -year-old children, it was reported that there was a weak relationship between a duration of breastfeeding of less than 4 months and obesity, but there was no statistical significance, and exclusive breastfeeding was not protective for obesity (21). In this study, we did not find a relationship between breastfeeding duration and obesity. However, it was seen that children who were breastfed for less than 4 months were more likely to be obese and overweight than children who were breastfed for more than 6 months.

A complementary feeding period provides the opportunity to protect children from becoming obese and overweight (22). Complementary nutrition that is applied between 6 and 24 months becomes an important period affecting long-term health (23). The European Society for Paediatric Gastroenterology Hepatology and Nutrition states that complementary nutrition should not be initiated before the $17^{\text {th }}$ week or after the $26^{\text {th }}$ week and that exclusive breastfeeding or predominantly breastfeeding in the diet for 6 months is preferential (24). This study did not find a relationship between the initiation time of a complementary diet and obesity. Therefore, it is important to provide appropriate nutritional support in this period, considering the positive effects of complementary nutrition on a child's development and on their long-term health (25).

\section{Study Limitations}

The limitation of the study was evaluating the mothers' and children's appetite according to the mothers' declaration. Furthermore, larger sample size studies on this issue will be useful.

\section{Conclusion}

Obesity is a preventable public health problem. In this respect, it is important to identify influential factors and take necessary measures to prevent children from becoming obese and overweight. This study determined that the mothers' characteristics of having a BMI classification of overweight or obese, having an excessive appetite and being employed may be risk factors in the development of overweight and obese children. Increasing the awareness of mothers about their excess weight and their children's excess weight and providing appropriate training for mothers about the healthy feeding of their children can help prevent obesity in childhood.

\section{Ethics}

Ethics Committee Approval: Ethics committee approval was obtained from the Ethics Committee of Izmir University of Health Sciences, Tepecik Training and Research Hospital (approval number: 2019/7-25).

Informed Consent: Informed consent was obtained from all mothers participating in the study.

Peer-review: Externally and internally peer-reviewed.

\section{Authorship Contributions}

Surgical and Medical Practices: Y.Ç.A., B.A., M.B., Concept: Y.Ç.A., M.B., Design: Y.Ç.A., M.B., O.B., B.A., Data Collection or Processing: Y.Ç.A., B.A., T.T., E.B., O.B., Analysis or Interpretation: Y.Ç.A., B.E., Literature Search: Y.Ç.A., B.E., T.T., E.B., Writing: Y.Ç.A., M.B.

Conflict of Interest: No conflict of interest was declared by the authors.

Financial Disclosure: The authors declared that this study received no financial support.

\section{References}

1. Önal Z, Adal E. Çocukluk çağında obezite. Eur Arc Med Res 2014;30:39-44.

2. Alpcan A, Durmaz ŞA. Çağımızın dev sorunu: Çocukluk çağı obezitesi. Turkish Journal of Clinics and Laboratory 2015:6:30-3. 
3. Must A, Jacques PF, Dallal GE, Bajema C), Dietz WH. Long-term morbidity and mortality of overweight adolescents. A followup of the Harvard Growth Study of 1922 to 1935. N Engl ) Med 1992;327:1350-5.

4. Heude B, Kettaneh A, Rakotovao R, et al. Anthropometric relationships between parents and children throughout childhood: the Fleurbaix-Laventie Ville Santé Study. Int I Obes (Lond) 2005;29:1222-9.

5. Andriani H, Liao CY, Kuo HW. Parenteral weight changes as key predictors of child weight changes. BMC Public Health 2015;15:645.

6. Silva Garcia K, Power TG, Fisher JO, O'Connor TM, Hughes SO. Latina mothers' influences on child appetite regulation. Appetite 2016;103:200-7.

7. Silva GK, Power TG, Beck AD, et al. Stability in the feeding practices and styles of low-income mothers: Questionnaire and observational analyses. Int J Behav Nutr Phys Act 2018;15:28.

8. Arenz S, Ruckerl R, Koletzko B, von Kries R. Breast-feeding and childhood obesity-a systematic review. Int I Obes Relat Metab Disord 2004;28:1247-56.

9. Wang I, Wu $Y$, Xiong $G$, et al. Introduction of complementary feeding before 4 months of age increases the risk of childhood overweight or obesity: A meta-analysis of prospective cohort studies. Nutr Res 2016;36:759-70.

10. Kuczmarski RJ, Ogden CL, Guo SS, et al. 2000 CDC growth charts for the United States: Methods and development. Vital Health Stat 11 2002:1-190.

11. Bundak R, Furman A, Gunoz H, Darendeliler F, Bas F, Neyzi O. Body mass index references for Turkish children. Acta Paediatr 2006;95:194-8

12. Faith MS, Van Horn L, Appel L), et al. Evaluating parents and adult caregivers as "agents of change" for treating obese children: Evidence for parent behavior change strategies and research gaps: A scientific statement from the American Heart Association. Circulation 2012;125:1186-207.

13. Boutelle KN, Cafri G, Crow SJ. Parent predictors of child weight change in family based behavioral obesity treatment. Obesity (Silver Spring) 2012;20:1539-43.

14. Whitaker RC, Wright JA, Pepe MS, Seidel KD, Dietz WH. Predicting obesity in young adulthood from childhood and parental obesity. N Engl ) Med 1997;337:869-73.
15. Stunkard AJ, Berkowitz RI, Stallings VA, Cater JR. Weights of parents and infants: is there a relationship? Int J Obes Relat Metab Disord 1999;23:159-62.

16. Wen LM, Baur LA, Simpson JM, Rissel C. Mothers' awareness of their weight status and concern about their children being overweight: Findings from first-time mothers in south-west Sydney. Aust N Z I Public Health 2010;34:293-7.

17. Huus K, Ludvigsson JF, Enskar K, Ludvigsson J. Risk factors in childhood obesity-findings from the all babies in Southeast Sweden (ABIS) cohort. Acta Paediatr 2007;96:1321-5.

18. Ziol-Guest KM, Dunifon RE, Kalil A. Parental employment and children's body weight: Mothers, others, and mechanisms. Soc Sci Med 2013;95:52-9.

19. Penilla C, Tschann JM, Sanchez-Vaznaugh EV, Flores E, Ozer E). Obstacles to preventing obesity in children aged 2 to 5 years: Latino mothers' and fathers' experiences and perceptions of their urban environments. Int I Behav Nutr Phys Act 2017;14:148.

20. Tambalis KD, Mourtakos S, Panagiotakos DB, Sidossis LS. Association of exclusive breastfeeding with risk of obesity in childhood and early adulthood. Breastfeed Med 2018.

21. Huus K, Ludvigsson JF, Enskär K, Ludvigsson J. Exclusive breastfeeding of Swedish children and its possible influence on the development of obesity: A prospective cohort study. BMC Pediatr 2008;8:42.

22. Bhutta ZA, Das JK, Rizvi A, et al. Evidence-based interventions for improvement of maternal and child nutrition: What can be done and at what cost? Lancet 2013;382:452-77.

23. Vitta BS, Benjamin $M$, Pries $A M$, Champeny $M$, Zehner $E_{\text {, }}$ Huffman SL. Infant and young child feeding practices among children under 2 years of age and maternal exposure to infant and young child feeding messages and promotions in Dar es Salaam, Tanzania. Matern Child Nutr 2016;12(Suppl 2):77-90.

24. Fewtrell $M$, Bronsky I, Campoy $C$, et al. Complementary feeding: A position paper by the European Society for Paediatric Gastroenterology, Hepatology, and Nutrition (ESPCHAN) Committee on Nutrition. I Pediatr Gastroenterol Nutr 2017;64:119-32.

25. Michaelsen KF, Grummer-Strawn L, Bégin F. Emerging issues in complementary feeding: Global aspects. Matern Child Nutr 2017;13(Suppl 2). 